\title{
Effects of Chemical Modification of Ursodeoxycholic Acid on TGR5 Activation
}

\author{
Yusuke Iguchi, ${ }^{*, a}$ Tomoko Nishimaki-Mogami ${ }^{b}$ Masafumi Yamaguchi, ${ }^{a}$ Fumiteru Teraoka, ${ }^{a}$ \\ Tetsuo KANEKo, ${ }^{a}$ and Mizuho $\mathrm{UNE}^{a}$ \\ ${ }^{a}$ Faculty of Pharmaceutical Science, Hiroshima International University; 5-1-1 Hirokoshingai, Kure, Hiroshima \\ 737-0112, Japan: and ${ }^{b}$ Division of Functional Biochemistry and Genomics, National Institute of Health Sciences; 1-18-1 \\ Kamiyoga, Setagaya-ku, Tokyo 158-8501, Japan.
}

Received August 18, 2010; accepted October 29, 2010; published online November 5, 2010

The aim of this study is to examine the ability of the bile acid analogues obtained by chemical modification of ursodeoxycholic acid (UDCA) for TGR5 activation. Eleven UDCA analogues including 3- or 7-methylated UDCAs and amino acid conjugates were investigated as to their ability to activate TGR5 by means of the luciferase assay. It was noteworthy that $7 \alpha$-methylated UDCA, namely $3 \alpha, 7 \beta$-dihydroxy-7 $\alpha$-methyl-5 $\beta$-cholanoic acid, had a significantly high affinity for and ability to activate TGR5 as compared to UDCA. Additionally, FXR activation ability of $7 \alpha$-methylated UDCA was low relative to that of UDCA. However, other modification of UDCA, such as the introduction of methyl group at its C-3 position and oxidation or epimerization of hydroxyl group in the $\mathbf{C}-3$ position, could not elicit such remarkable effect. The present findings would provide a useful strategy for the development of TGR5-selective agonist.

Key words TGR5; ursodeoxycholic acid; structure-activity relationship; farnesoid X receptor; metabolic syndrome

Ursodeoxycholic acid $(3 \alpha, 7 \beta$-dihydroxy- $5 \beta$-cholanoic acid, UDCA) is a major bile acid in the bile obtained from some bears, ursidae. ${ }^{1)}$ Fel Ursi (Yutan) is prepared from the dry gallbladder bile of adult bears and has been used as a drug of animal origins since ancient times. While UDCA is in use as a therapeutic agent for dissolution of cholesterol gallstones in humans ${ }^{2)}$ this naturally occurring bile acid has been shown to be efficient for the improvement of liver function in patients with diverse liver diseases, including chronic hepatitis $\mathrm{C}$ and primary biliary cirrhosis. ${ }^{3-5)}$ These effects could not be detected in other bile acids. UDCA is structurally unique in that it possesses a $\beta$-oriented hydroxyl group at the $\mathrm{C}-7$ position as compared to other naturally occurring bile acids. Although the molecular mechanism underlying the efficacy of UDCA is still not evident, the presence of the equatorial $7 \beta$-hydroxyl group may contribute to the liver-function improvement activity of UDCA.

It has recently been shown that bile acids are endogenous ligands of the farnesoid X receptor (FXR), and that chenodeoxycholic acid (CDCA) is the most potent ligand. ${ }^{6,7)}$ CDCA along with cholic acid (CA) is the major constituent of human bile, and both bile acids possess a $7 \alpha$-hydroxyl group, like many other bile acids. CDCA was shown to bind to and activate FXR, leading to enhanced transcription of specific target genes associated with the biosynthesis and enterohepatic circulation of bile acids, as well as with the metabolism of cholesterol, triglyceride and glucose. ${ }^{8,9)}$ Thus, the stimulation of FXR with bile acids has become a promising novel drug strategy for the treatment of common metabolic diseases. However, UDCA shows little ability for the FXR stimulation. ${ }^{6,10)}$

Recently, it has also been reported that bile acids could stimulate the G-protein-coupled receptor, TGR5, expressed on the cell surface. ${ }^{11,12)}$ The TGR5 signaling pathway modulates energy expenditure by controlling the activity of type 2 iodothyronine deiodinase and the subsequent activation of thyroid hormone in brown adipose tissue and muscle, leading to prevention of obesity. ${ }^{13,14)}$ This finding implies that a TGR5-activating drug may be efficacious in the treatment of various metabolic disorders associated with weight gain.

This study was carried out in order to develop new drugs that would regulate energy expenditure via activation of TGR5 in an FXR independent-manner. We focused on bile acids that exhibit no or slight FXR agonist activity; we developed diverse UDCA derivatives by chemical modification, including alkylation, oxidation, or conjugation with amino acids, and have examined their ability for TGR5 activation and the subsequent induction of cAMP production. This approach may pave the way for a new strategy to develop new pharmacological approaches for the treatment of the metabolic syndrome, including type 2 diabetes.

\section{MATERIALS AND METHODS}

General TLC was performed on silica gel precoated TLC aluminum sheets ( $0.2 \mathrm{~mm}$ thickness, Merck, Germany). NMR spectra were measured at $600 \mathrm{MHz}$ on a JEOL ECA600 spectrometer using chloroform- $d_{5}$ as a solvent and tetramethylsilane as internal standard. GC-MS was carried out on GCMS-QP2010 (Shimadzu, Kyoto, Japan) under the following conditions: column, DB-1MS $(0.25 \mathrm{~mm} \times 15.0 \mathrm{~m})$; column oven temperature, $70-250^{\circ} \mathrm{C}$ at a rate of $20^{\circ} \mathrm{C} / \mathrm{min}$ with initial time of $1 \mathrm{~min}$, followed by $250-290^{\circ} \mathrm{C}$ at a rate of $2{ }^{\circ} \mathrm{C} / \mathrm{min}$ with final time of $2 \mathrm{~min}$; injection port temperature, $300^{\circ} \mathrm{C}$; ion source temperature, $200^{\circ} \mathrm{C}$; pressure of helium carrier gas, $150 \mathrm{kPa}$; ionizing voltage, $70 \mathrm{~V}$. Bile acid samples were treated with freshly prepared ethereal diazomethane solution at room temperature for $1 \mathrm{~h}$, and the resulting methyl esters were chromatographed as their trimethylsilyl (TMS) ether derivatives.

Bile Acid and UDCA Derivatives The molecular structures of UDCA and its analogues were shown in Fig. 1A. Lithocholic acid (LCA), CDCA, UDCA and CA were commercial products. $3 \beta, 7 \beta$-Dihydroxy- $5 \beta$-cholanoic acid (1), 
A

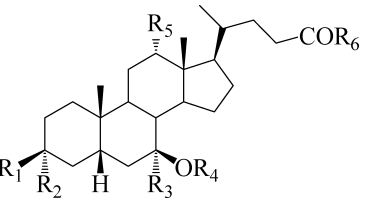

\begin{tabular}{|c|c|c|c|c|c|c|}
\hline Compounds & $\mathrm{R}_{1}$ & $\mathrm{R}_{2}$ & $\mathrm{R}_{3}$ & $\mathrm{R}_{4}$ & $\mathrm{R}_{5}$ & $\mathrm{R}_{6}$ \\
\hline UDCA & $-\mathrm{H}$ & $-\mathrm{OH}$ & $-\mathrm{H}$ & $-\mathrm{H}$ & $-\mathrm{H}$ & $-\mathrm{OH}$ \\
\hline UDC-tau & $-\mathrm{H}$ & $-\mathrm{OH}$ & $-\mathrm{H}$ & $-\mathrm{H}$ & $-\mathrm{H}$ & $-\mathrm{NHCH}_{2} \mathrm{CH}_{2} \mathrm{SO}_{3} \mathrm{H}$ \\
\hline UDC-gly & $-\mathrm{H}$ & $-\mathrm{OH}$ & $-\mathrm{H}$ & $-\mathrm{H}$ & $-\mathrm{H}$ & $-\mathrm{NHCH}_{2} \mathrm{COOH}$ \\
\hline (1) & $-\mathrm{OH}$ & $-\mathrm{H}$ & $-\mathrm{H}$ & $-\mathrm{H}$ & $-\mathrm{H}$ & $-\mathrm{OH}$ \\
\hline (2) & $-\mathrm{H}$ & $-\mathrm{OH}$ & $-\mathrm{H}$ & $-\mathrm{H}$ & $-\mathrm{OH}$ & $-\mathrm{OH}$ \\
\hline (3) & $=\mathrm{O}$ & $=\mathrm{O}$ & $-\mathrm{H}$ & $-\mathrm{H}$ & $-\mathrm{H}$ & $-\mathrm{OH}$ \\
\hline (4) & $-\mathrm{CH}_{3}$ & $-\mathrm{OH}$ & $-\mathrm{H}$ & $-\mathrm{H}$ & $-\mathrm{H}$ & $-\mathrm{OH}$ \\
\hline (5) & $-\mathrm{OH}^{3}$ & $-\mathrm{CH}_{3}$ & $-\mathrm{H}$ & $-\mathrm{H}$ & $-\mathrm{H}$ & $-\mathrm{OH}$ \\
\hline (6) & $-\mathrm{H}$ & $-\mathrm{OH}^{3}$ & $-\mathrm{CH}_{3}$ & $-\mathrm{H}$ & $-\mathrm{H}$ & $-\mathrm{OH}$ \\
\hline (7) & $-\mathrm{H}$ & $-\mathrm{OH}$ & $-\mathrm{H}$ & $-\mathrm{SO}_{3} \mathrm{H}$ & $-\mathrm{H}$ & $-\mathrm{OH}$ \\
\hline (8) & $-\mathrm{H}$ & $-\mathrm{OH}$ & $-\mathrm{H}$ & $-\mathrm{H}$ & $-\mathrm{H}$ & $\begin{array}{c}-\mathrm{NH}-\mathrm{CH}-\mathrm{COOH} \\
\stackrel{\mathrm{C}}{\mathrm{C}} \mathrm{H}_{2} \mathrm{OH}\end{array}$ \\
\hline (9) & $-\mathrm{H}$ & $-\mathrm{OH}$ & $-\mathrm{H}$ & $-\mathrm{H}$ & $-\mathrm{H}$ & $-\underset{\text { COOH }}{-\mathrm{NH}-\mathrm{CH}_{2}-\mathrm{CH}_{2} \mathrm{SO}_{3} \mathrm{H}}$ \\
\hline (10) & $-\mathrm{H}$ & $-\mathrm{OH}$ & $-\mathrm{H}$ & $-\mathrm{H}$ & $-\mathrm{H}$ & $-\mathrm{NH}-7 \mathrm{COOH}$ \\
\hline (11) & $-\mathrm{H}$ & $-\mathrm{OH}$ & $-\mathrm{CH}_{3}$ & $-\mathrm{H}$ & $-\mathrm{H}$ & $-\mathrm{NHCH}_{2} \mathrm{CH}_{2} \mathrm{SO}_{3} \mathrm{H}$ \\
\hline
\end{tabular}

B

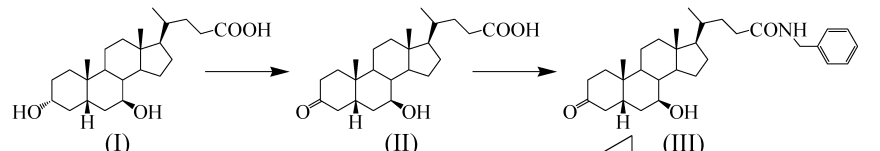

(I)

(II)

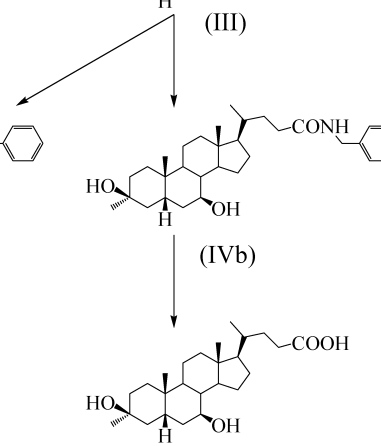

$(\mathrm{Vb})$

Fig. 1. Structures of UDCA Analogues (A) and Synthesis of 3-Methylated UDCA (B)

(A) UDCA, $3 \alpha, 7 \beta$-dihydroxy-5 $\beta$-cholanoic acid; UDC-tau, ursodeoxycholyl taurine; UDC-gly, ursodeoxycholyl glycine; (1), $3 \beta, 7 \beta$-dihydroxy-5 $\beta$-cholanoic acid; (2) $3 \alpha, 7 \beta, 12 \alpha$-trihydroxy- $5 \beta$-cholanoic acid; (3), $7 \beta$-hydroxy-3-oxo- $5 \beta$-cholanoic acid; (4), $3 \alpha, 7 \beta$-dihydroxy- $3 \beta$-methyl- $5 \beta$-cholanoic acid; (5), $3 \beta, 7 \beta$-dihydroxy- $3 \alpha$-methyl$5 \beta$-cholanoic acid; (6), $3 \alpha, 7 \beta$-dihydroxy- $7 \alpha$-methyl-5- $\beta$-cholanoic acid ( $7 \alpha$-MeUDCA); (7), $3 \alpha$-hydroxy-7 $\beta$-sulfooxy- $5 \beta$-cholanoic acid (UDCA-7- $O$-sulfate); (8), ursodeoxycholyl serine; (9), ursodeoxycholyl-L-cysteic acid; (10), ursodeoxycholyl $p$ aminobenzoic acid (UDC-PABA); (11), $7 \alpha$-methyl-ursodeoxycholyl taurine. (B) (I), UDCA; (II), $7 \beta$-hydroxy-3-oxo-5 $\beta$-cholanoic acid; (III), $N$-[7 $\beta$-hydroxy-3,24-dioxo$5 \beta$-cholan-24-yl]-benzylamine; $\quad$ (IVa),$\quad N$-[3 $\alpha, 7 \beta$-dihydroxy-3 $\beta$-methyl-24-oxo-5 $\beta$ cholan-24-yl]-benzylamine; (IVb), $N$-[3 $\beta, 7 \beta$-dihydroxy-3 $\alpha$-methyl-24-oxo-5 $\beta$-cholan24 -yl]-benzylamine; (Va), $3 \alpha, 7 \beta$-dihydroxy- $3 \beta$-methyl-5 $\beta$-cholanoic acid; $(\mathrm{Vb})$, $3 \beta, 7 \beta$-dihydroxy-3 $\alpha$-methyl-5 $\beta$-cholanoic acid. Compounds in the figure are indicated by bracketed numbers.

$3 \alpha, 7 \beta, 12 \alpha$-trihydroxy- $5 \beta$-cholanoic acid (2) were synthesized according to the method reported previously. ${ }^{15)} \mathrm{Ur}$ sodeoxycholyl taurine (UDC-tau), ursodeoxycholyl glycine (UDC-gly), ursodeoxycholyl serine (8), ursodeoxycholyl Lcysteic acid (9), and ursodeoxycholyl $p$-aminobenzoic acid (10) were prepared as reported previously. ${ }^{16,17)} 3 \alpha$-Hydroxy$7 \beta$ - $O$-sulfo- $5 \beta$-cholanoic acid (7) was synthesized from
UDCA according to previously reported manner. ${ }^{18)} 3 \alpha, 7 \beta$ Dihydroxy- $7 \alpha$-methyl- $5 \beta$-cholanoic acid (6) and its taurine conjugate (11) were also prepared as the manner reported previously by us. ${ }^{19)} 7 \beta$-Hydroxy-3-oxo- $5 \beta$-cholanoic acid (3), $3 \alpha, 7 \beta$-dihydroxy- $3 \beta$-methyl-5 $\beta$-cholanoic acid (4) and $3 \beta, 7 \beta$-dihydroxy- $3 \alpha$-methyl- $5 \beta$-cholanoic acid (5) were synthesized according to the following method.

Synthesis of $3 \alpha, 7 \beta$-Dihydroxy- $3 \beta$-methyl- $5 \beta$-cholanoic Acid and $3 \beta, 7 \beta$-Dihydroxy-3 $\alpha$-methyl-5 $\beta$-cholanoic Acid (Fig. 1B) $7 \beta$-Hydroxy-3-oxo-5 $\beta$-cholanoic acid (II) was prepared from ursodeoxycholic acid (I) by treatment with aluminum $t$-butoxide according to the method described previously. ${ }^{15)}$ The amidation of carboxyl group was carried out as reported previously. ${ }^{20)}$ In brief, a solution of II ( $\left.1.5 \mathrm{~g}\right)$ dissolved in $\mathrm{CH}_{2} \mathrm{Cl}_{2}(40 \mathrm{ml})$ was added benzylamine $(0.6 \mathrm{ml})$, 4dimethylaminopyridine $(24 \mathrm{mg})$ and 1-ethyl-3-(dimethylaminopropyl)-carbodiimide $\mathrm{HCl}$ salt $(880 \mathrm{mg})$ under stirring at $0^{\circ} \mathrm{C}$. The reaction mixture was kept at room temperature for $2 \mathrm{~h}$ and diluted with ice-cold water. The reaction products were extracted with ethyl acetate $(400 \mathrm{ml})$ after acidification with dilute $\mathrm{HCl}$. The extracts were washed with water, $5 \%$ $\mathrm{NaHCO}_{3}$, and dried over anhydrous $\mathrm{Na}_{2} \mathrm{SO}_{4}$. Evaporation of the solvent left a residue (III, $1.4 \mathrm{~g}$ ). A $0.93 \mathrm{~m}$ tetrahydrofuran solution of methyl magnesium bromide $(20 \mathrm{ml})$ was added dropwise to a solution of III $(0.9 \mathrm{~g})$ dissolved in $100 \mathrm{ml}$ of dry benzene. The reaction mixture was refluxed at $90^{\circ} \mathrm{C}$ for $2 \mathrm{~h}$, poured into ice cold water, and extracted with ethyl ether after acidification with dilute $\mathrm{HCl}$. The extracts were washed with water to neutrality, dried over anhydrous $\mathrm{Na}_{2} \mathrm{SO}_{4}$, and evaporated to dryness. The residue was chromatographed on a column of silica gel $(70 \mathrm{~g}$, silica gel G, $35-70$ mesh) using a mixture of ethyl acetate and acetone as an eluting solvent. Elution with a 9:1 mixture of ethyl acetate-acetone and crystallization from acetone gave a residue $(240 \mathrm{mg}$ ) of $N$-[3 $3,7 \beta$-dihydroxy-3 $\alpha$-methyl-24-oxo$5 \beta$-cholan-24-yl]-benzylamine (IVb). ${ }^{1} \mathrm{H}-\mathrm{NMR}(\delta \mathrm{ppm})$; $0.64\left(18-\mathrm{CH}_{3}, 3 \mathrm{H}, \mathrm{s}\right), 0.91\left(21-\mathrm{CH}_{3}, 3 \mathrm{H}, \mathrm{d}, J=6.2 \mathrm{~Hz}\right), 0.96$ $\left(19-\mathrm{CH}_{3}, 3 \mathrm{H}, \mathrm{s}\right), 1.18\left(3 \alpha-\mathrm{CH}_{3}, 3 \mathrm{H}, \mathrm{s}\right), 3.50(7 \alpha-\mathrm{H}, 1 \mathrm{H}, \mathrm{m})$. ${ }^{13} \mathrm{C}-\mathrm{NMR}(\delta \mathrm{ppm}) ; 31.6\left(3 \alpha-\mathrm{CH}_{3}, \mathrm{q}\right), 70.0(\mathrm{C}-3, \mathrm{~s})$. GC-MS, $\mathrm{m} / \mathrm{z}$ (fragment ion, relative intensity); $639\left(\mathrm{M}^{+}, 32 \%\right), 624$ (M-15, 66\%), 549 (M-90, 48\%), $534(\mathrm{M}-90-15,21 \%)$, $459(\mathrm{M}-2 \times 90$, base peak), $444(\mathrm{M}-2 \times 90-15,72 \%), 311$ (78\%), $269(\mathrm{M}-2 \times 90-$ side chain, 74\%), 257 (C3-C7, $65 \%)$. IVb (100 mg) was hydrolyzed with ethanolic $2 \mathrm{~N} \mathrm{NaOH}$ $(50 \mathrm{ml})$. The reaction mixture was diluted with water and extracted with ethyl acetate $(200 \mathrm{ml})$ after acidification with dilute $\mathrm{HCl}$. The organic layer was washed with water, dried over anhydrous $\mathrm{Na}_{2} \mathrm{SO}_{4}$, and evaporated to dryness to give a amorphous white powder of $3 \beta, 7 \beta$-dihydroxy- $3 \alpha$-methyl$5 \beta$-cholanoic acid (Vb). ${ }^{1} \mathrm{H}-\mathrm{NMR} ; 0.70\left(18-\mathrm{CH}_{3}, 3 \mathrm{H}, \mathrm{s}\right)$, $0.94\left(21-\mathrm{CH}_{3}, 3 \mathrm{H}, \mathrm{d}, J=6.2 \mathrm{~Hz}\right), 0.98\left(19-\mathrm{CH}_{3}, 3 \mathrm{H}, \mathrm{s}\right), 1.16$ $\left(3 \alpha-\mathrm{CH}_{3}, 3 \mathrm{H}, \mathrm{s}\right), 3.40(7 \alpha-\mathrm{H}, 1 \mathrm{H}, \mathrm{m}) .{ }^{13} \mathrm{C}-\mathrm{NMR} ; 31.8(3 \alpha-$ $\left.\mathrm{CH}_{3}, \mathrm{q}\right), 70.6(\mathrm{C}-3, \mathrm{~s})$. GC-MS, $m / z ; 564\left(\mathrm{M}^{+}, 2 \%\right), 549$ $(\mathrm{M}-15,10 \%), 474(\mathrm{M}-90,82 \%), 384(\mathrm{M}-2 \times 90$, base peak), $369(\mathrm{M}-2 \times 90-15, \quad 19 \%), \quad 331 \quad(15 \%), \quad 269$ (M-2×90-side chain, 12\%), $257(\mathrm{C} 3-\mathrm{C} 7,32 \%)$.

The fractions eluted with a $8: 2$ mixture of ethyl acetate-acetone gave a residue $(250 \mathrm{mg})$ of $N-[3 \alpha, 7 \beta$-dihydroxy-3 $\beta$-methyl-24-oxo- $5 \beta$-cholan-24-yl]-benzylamine (IVa), ${ }^{1} \mathrm{H}-\mathrm{NMR} ; 0.64\left(18-\mathrm{CH}_{3}, 3 \mathrm{H}, \mathrm{s}\right), 0.90\left(21-\mathrm{CH}_{3}, 3 \mathrm{H}, \mathrm{d}\right.$, $J=6.2 \mathrm{~Hz}), 0.94\left(19-\mathrm{CH}_{3}, 3 \mathrm{H}, \mathrm{s}\right), 1.22\left(3 \beta-\mathrm{CH}_{3}, 3 \mathrm{H}, \mathrm{s}\right), 3.56$ 
(7 $\alpha-\mathrm{H}, 1 \mathrm{H}, \mathrm{m}) .{ }^{13} \mathrm{C}-\mathrm{NMR} ; 26.1\left(3 \beta-\mathrm{CH}_{3}, \mathrm{q}\right), 71.8(\mathrm{C}-3, \mathrm{~s})$. GC-MS, $m / z ; 639\left(\mathrm{M}^{+}, 3 \%\right), 624(\mathrm{M}-15,19 \%), 549(\mathrm{M}-$ 90, 33\%), $534(\mathrm{M}-90-15,4 \%), 459$ (M-2×90, 31\%), 444 $(\mathrm{M}-2 \times 90-15,18 \%), 311(16 \%), 269(\mathrm{M}-2 \times 90-$ side chain, base peak), 257 (C3-C7, 21\%). IVa (100 mg) was hydrolyzed with ethanolic $2 \mathrm{~N} \mathrm{NaOH}(50 \mathrm{ml})$. The reaction mixture was diluted with water and extracted with ethyl acetate after acidification with dilute $\mathrm{HCl}$. The organic layer was washed with water, dried over anhydrous $\mathrm{Na}_{2} \mathrm{SO}_{4}$, and evaporated to dryness to give amorphous powder of $3 \alpha, 7 \beta$ dihydroxy-3 $\beta$-methyl-5 $\beta$-cholanoic acid (Va). ${ }^{1} \mathrm{H}-\mathrm{NMR} ; 0.71$ $\left(18-\mathrm{CH}_{3}, 3 \mathrm{H}, \mathrm{s}\right), 0.95\left(21-\mathrm{CH}_{3}, 3 \mathrm{H}, \mathrm{d}, J=6.2 \mathrm{~Hz}\right), 0.98$ (19$\left.\mathrm{CH}_{3}, 3 \mathrm{H}, \mathrm{s}\right), 1.19\left(3 \beta-\mathrm{CH}_{3}, 3 \mathrm{H}, \mathrm{s}\right), 3.46(7 \alpha-\mathrm{H}, 1 \mathrm{H}, \mathrm{m}) .{ }^{13} \mathrm{C}-$ NMR; $25.9\left(3 \beta-\mathrm{CH}_{3}, \mathrm{q}\right), 72.2(\mathrm{C} 3, \mathrm{~s}) . \mathrm{GC}-\mathrm{MS} ; 564\left(\mathrm{M}^{+}\right.$, 10\%), 549 (M-15, 16\%), 474 (M-90, 81\%), $384(\mathrm{M}-2 \times$ 90, base peak), 369 (M-2×90-15, 18\%), 331 (41\%), 269 $(\mathrm{M}-2 \times 90-$ side chain, 17\%), 257 (C3-C7, 66\%).

The configuration of methyl group at C-3 was tentatively assigned based on the chemical sifts of ${ }^{13} \mathrm{C}$-NMR since an equatorial methyl substituent is known to give smaller chemical shift than that of an axial counterpart. ${ }^{21}$ )

Transient Transfections and Reporter Gene Assays Human embryonic kidney cell line 293T (Hek293T cells) seeded at $50-60 \%$ confluence in 96 -well plates were maintained in Dulbecco's modified Eagle's medium (DMEM) containing $10 \%$ fetal calf serum for $24 \mathrm{~h}$ prior to transfection. For transient transfections, cells were rinsed with phosphate buffered saline (PBS) (-) and were transfected with $12.5 \mathrm{ng} /$ well of cAMP response element (CRE)-driven luciferase reporter constructs (SA Bioscience, Frederick, MD, U.S.A.) and $18.75 \mathrm{ng} /$ well of human TGR5 expression plasmid (pCMVSPORT6/hTGR5, Invitrogen, Carlsbad, CA, U.S.A.) by using Attractene Transfection Reagent (Qiagen, Chatsworth, CA, U.S.A.) in OPTI-MEM I reduced-serum medium (Invitrogen). Six hours after the transfection, a volume of DMEM containing 20\% fetal calf serum equivalent to the amount of transfection media used were added to the cells. After further $18 \mathrm{~h}$ incubation, the cells were washed once with $\mathrm{PBS}(-)$ and were treated for $5 \mathrm{~h}$ with different concentrations of each compound in fresh DMEM containing $0.5 \%$ delipidated serum. After treatment, the cells were then lysed and luciferase activity was determined using Dual-Luciferase $^{\circledR}$ Reporter Assay System (Promega, Madison, WI, U.S.A.) according to the manufacturer's instructions. The firefly luciferase activity was normalized to Renilla luciferase activity for each well.

To evaluate the FXR agonist activity, human hepatoma cells (Huh-7) were transfected with 188 ng pFXRE-tk-Luc, $\left.{ }^{10}\right)$ $63 \mathrm{ng}$ each of the pcDNA3.1 expression vectors for human $\operatorname{FXR} \alpha$ and retinoid X receptor $\alpha$, and 313 ng of the pSV- $\beta$ galactosidase vector (Promega) with Attractene (Qiagen). Six hours after the transfection, the cells were exposed to bile acid analogues for $20 \mathrm{~h}$ in a medium containing $0.5 \%$ delipidated serum. The cells were then lysed, followed by determination of the luciferase activity. The firefly luciferase activity was normalized to the $\beta$-galactosidase activity for each well.

Reverse Transcription Polymerase Chain Reaction (RTPCR) Human TGR5 mRNA expression was verified by RT-PCR using gene-specific primers. Primers for human TGR5 were: sense 5'-GGA GCG GGC AGT GTG CCG CGA TGA G-3' and antisense 5'-TTA GTT CAA GTC CAG
GTC CAC ACT G-3' yielding a 390-bp product (Invitrogen), and for human glyceraldehyde-3-phosphate dehydrogenase (GAPDH) were: sense 5'-TGC CTC CTG CAC CAC CAA CT-3' and antisense 5'-CGC CTG CTT CAC CAC CTT C-3' yielding a 349-bp product (Invitrogen). Hek293T cells were transfected with mock (pCMVSPORT6) or hTGR5 plasmids according to the protocol noted above. Total RNA was isolated from cells using the SV Total RNA Isolation System (Promega) according to the manufacturer's instructions. Reverse transcription was performed by Transcriptor First Strand cDNA Synthesis Kit (Roche Biochemicals, Basel, Switzerland) according to the manufacturer's instructions. The cDNA product was amplified by PCR with AmpliTaq Gold (Applied Biosystems, Foster City, CA, U.S.A.) using previously described protocol. ${ }^{11)}$ The amplified products were separated on $2 \%$ agarose gels, stained with ethidium bromide, and photographed using ultraviolet illumination.

Immunofluorescence and Confocal Laser Scanning Microscopy For immunofluorescence studies, Hek293T cells were seeded in poly-D-lysine-coated culture slide (BD Biosciences, Franklin Lakes, NJ, U.S.A.) for $24 \mathrm{~h}$ before transfection. Cells were transfected with hTGR5 plasmid or mock plasmid and were co-transfected with DsRed (Clontech, Palo Alto, CA, U.S.A.) as a transfection control. After $24 \mathrm{~h}$ incubation, the cells were fixed in $4 \%$ paraformaldehyde/PBS $(-)$ solution and were permeabilized with $0.2 \%$ tritonX-100/ $\operatorname{PBS}(-)$ solution. The slide was rinsed with $\operatorname{PBS}(-)$ and then incubated with anti-human TGR5 antibody (ABR, Golden, CO, U.S.A.) in $1 \%$ bovine serum albumin (BSA)/ $\operatorname{PBS}(-)$ solution $\left(1: 300\right.$ dilution) at $4{ }^{\circ} \mathrm{C}$ for overnight. Then the slide was incubated with anti-rabbit immunoglobulin $\mathrm{G}$ ( $\mathrm{IgG}$ ) antibody coupled to fluorescein isothiocyanate (FITC) (DAKO Cytomation, Glostrup, Denmark) in 1\% BSA/PBS $(-)$ solution (1:400 dilution). The slide was then washed with $\mathrm{PBS}(-)$, and coverslip were mounted with vectashield mounting medium (Vector Laboratories, Burlingame, CA, U.S.A.), and sealed with nail polish. Cells were viewed using Olympus Fluoview FV300 confocal microscope (Olympus, Tokyo, Japan).

cAMP Production Analysis Hek293T cells, in which hTGR5 plasmid was transiently transfected by the above method, were washed with $\operatorname{PBS}(-)$, and medium was exchanged for cAMP assay medium [DMEM containing $0.1 \%$ (w/v) BSA and 0.5 mm 3-isobutyl-1-methylxanthine (IBMX)]. After incubation for $30 \mathrm{~min}$ at $37^{\circ} \mathrm{C}$, the cells were treated with each compound in fresh cAMP assay medium for 30 min. After treatment, cAMP amounts were determined using cAMP screen kit (Applied Biosystems) according to the manufacturer's instructions.

$\mathbf{5 0 \%}$ Effective Concentrations $\left(\mathrm{EC}_{\mathbf{5 0}}\right)$ and Efficacy Determination Assays were performed in triplicate for each condition. $\mathrm{EC}_{50}$ values of each compound were calculated with probit analysis. TGR5 and FXR agonist activity was determined by calculating percentages of $1 \mu \mathrm{M}$ LCA value and of $10 \mu \mathrm{M}$ CDCA value, respectively.

Statistical Analysis Statistical analysis was performed by Student's $t$ test, and $p<0.05$ was considered statistically significant. 


\section{RESULTS}

Diverse bile acid derivatives possessing a $7 \beta$-hydroxyl group, as shown in Fig. 1A, were prepared and evaluated, a transient transfection assay, for their ability for TGR5 activation. For cell toxicities of these UDCA analogues, the viabilities of Hek293T cells were validated by 3-(4,5-dimethylthiazol-2-yl)-2,5-diphenyltetrazolium bromide (MTT) assay to use as ref. 22, and then the cell toxicities of UDCA analogues used in this study were not observed (data not shown).

In order to determine the experimental conditions, at first, human TGR5 expression plasmids were transfected transiently into different three cell lines. As shown in Fig. 2A, significant activity of CRE-driven luciferase by LCA treatment was observed only in Hek293T cells, but not in the Huh-7 and Chinese hamster ovary (CHO) cells. In addition, no luciferase activity was observed at all in Hek293T cells transfected with a mock plasmid. Furthermore, hTGR5 mRNA expression was confirmed in the Hek293T cells transfected with hTGR5 plasmids using RT-PCR analysis (Fig. 2B), and the protein was also detected on the surface of the plasma membrane (Fig. 2C). Thus, Hek293T cells were employed for the present study.

Figure $3 \mathrm{~A}$ shows the effects of a series of UDCA analogues chemically modified in the steroid nucleus on TGR5 activation. The $3 \beta$-isomer of UDCA (1), $12 \alpha$-hydroxylated UDCA (2) and 7 $\beta$-hydroxy-3-oxo-5 $\beta$-cholanoic acid (3), showed a weaker ability for TGR5 activation than UDCA. 3Methylated UDCA analogues ((4), (5)) showed a slightly weaker activity, whereas $7 \alpha$-methylated UDCA (6) showed a stronger activity than UDCA. On the other hand, UDCA-7$O$-sulfate (7) scarcely activated TGR5.

We also examined the ability of UDCA conjugated with various amino acids for TGR5 activation (Fig. 3B). Although conjugation with serine (8), as well as conjugation with taurine and glycine, was effective for TGR5 activation, the TGR5 agonist activity was strikingly decreased by conjugation with L-cysteic acid (9). Conjugation with $p$-aminobenzoic acid (UDC-PABA, (10)) enhanced the affinity for and ability to activate TGR5. In addition, $7 \alpha$-methylated UDCA conjugated with taurine (11) exhibited similar activity to that of UDC-tau, even though its affinity for TGR5 was significantly higher than that of UDC-tau.

In order to confirm the ability of UDCA analogues for modulation of intracellular signaling, the cAMP production was evaluated (Fig. 4). cAMP production was significantly induced by $7 \alpha$-methylated UDCA analogues $((\mathbf{6}),(\mathbf{1 1}))$ and UDC-PABA (10), although the concentrations required were about 10 -fold higher than that of LCA.

In order to evaluate the TGR5 selectivity, the FXR activation abilities of the UDCA derivatives were estimated (Table 1). Most of UDCA analogues exhibited little FXR agonist activity, however the degree of FXR activation induced by UDC-PABA (10) was more than twice as much as that by CDCA $(10 \mu \mathrm{M}) .7 \alpha$-Methylated UDCA (6) and its taurine conjugate (11) exhibited a decrease of the FXR agonist activity, leading to a decrease in the TGR5/FXR EC ${ }_{50}$ ratio calculated from the $\mathrm{EC}_{50}$ values for TGR5 and FXR (Table 1).
A

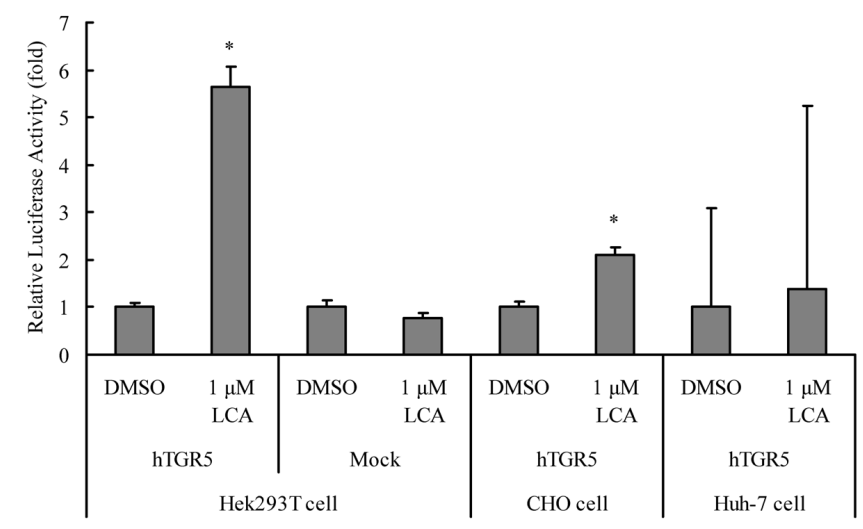

C
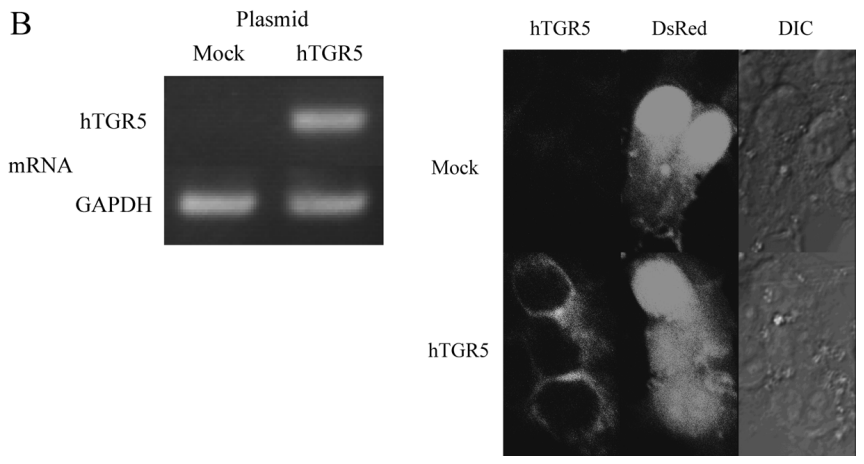

Fig. 2. The Activations of CRE-Luciferase Reporter Construct via TGR5 in the Cellular Transactivation Assay (A) and hTGR5 mRNA (B) and Protein (C) Expression in Hek293T Cells Transfected with hTGR5 Plasmid or Mock Plasmid

(A) Hek293T, CHO or Huh-7 cells were transfected with CRE-luciferase reporter constructs and a human TGR5 expression plasmid or mock plasmid. These cells were exposed to DMSO alone or $1 \mu \mathrm{M}$ of LCA. Firefly luciferase activity in the cell extract was normalized to Renilla luciferase activity and expressed as the fold induction relative to vehicle-exposed cells. The values are the means \pm S.D. of three experiments. $* p<0.01$ versus vehicle (DMSO)-treated cells. (B) Total RNA preparations were subjected to RT-PCR analysis. The amplified products were separated on $2 \%$ agarose gels, stained with ethidium bromide, and photographed using ultraviolet illumination. (C) Hek293T cells transfected with hTGR5 plasmid or mock plasmid and co-transfected with DsRed as a transfection control were stained using anti-human TGR5 antibody and FITC-conjugated anti-rabbit IgG antibody. DIC: differential interference contrast.

\section{DISCUSSION}

Bile acids had so far been mapped as endogenously bioactive substances, by which dietary lipids and fat-soluble vitamins were simply solubilized, followed by their digestion and absorption. However, it has recently been shown that bile acids function as signaling molecules controlling not only the synthesis of primary bile acids, but also the metabolism of triglycerides, glucose and energy via FXR or TGR5. ${ }^{23,24)}$ In the context of these observations, we examined the structure-activity relationships between each of these receptors and bile acid analogues for the purpose of drug development for the treatment of metabolic syndrome. ${ }^{10,25-29)}$ As a result, we demonstrated that bile acid analogues having chemical structures similar to the usual bile acids activate both the receptors to the same extent. In the case of in vivo studies, hence, it would be difficult to distinguish FXR- or TGR5-selectivity-limited effects of these bile acid analogues. In the above studies, UDCA exceptionally exhibited higher affinity for TGR5 rather than FXR. Therefore, we prepared diverse 


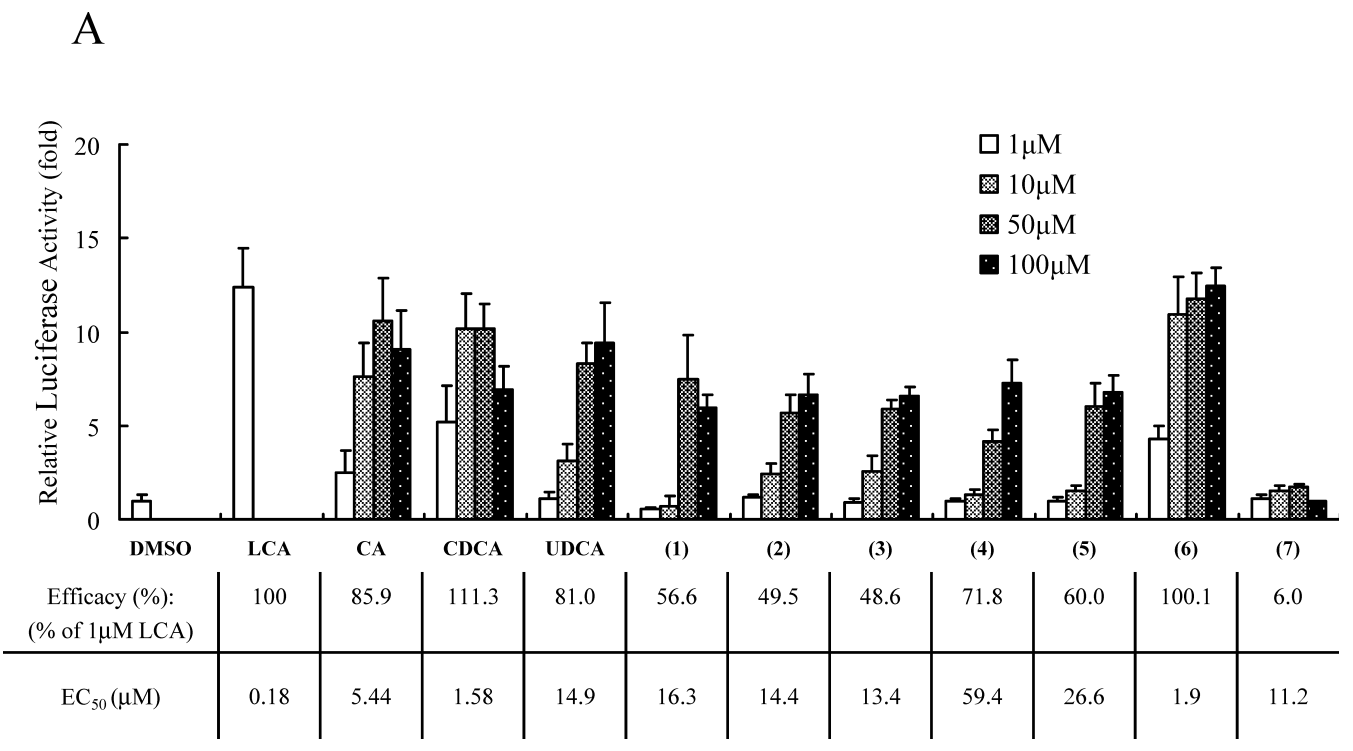

B

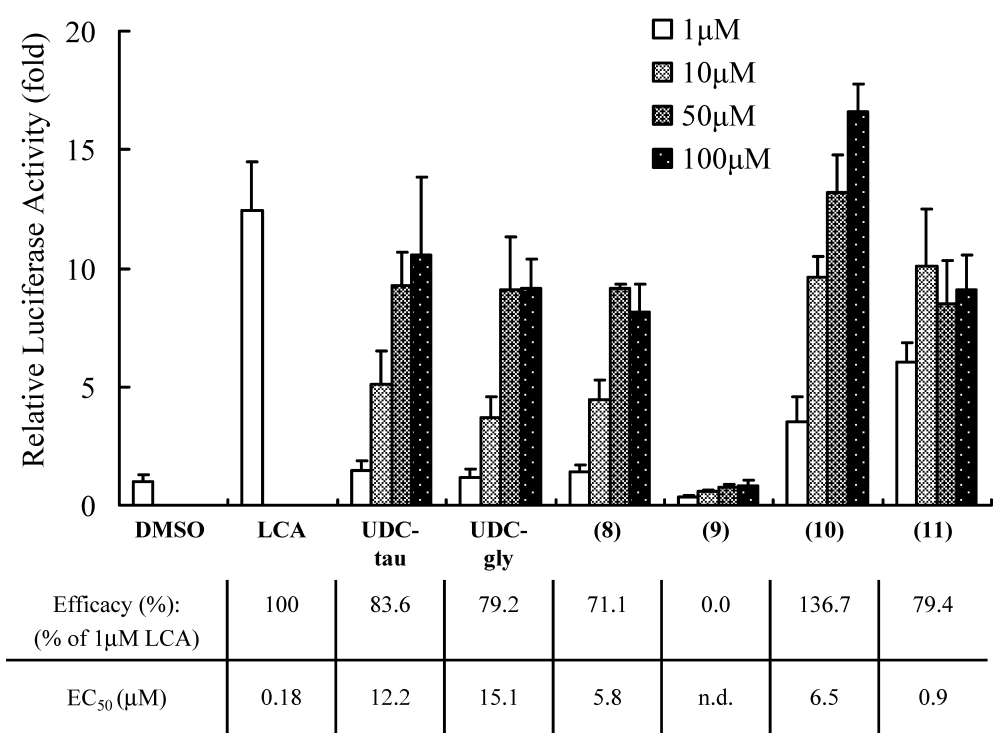

Fig. 3. The Effect of UDCA Analogues Prepared by Modification of Their Steroid Nucleus (A) and/or Side Chain (B) on TGR5 Activation in the Cellular Transactivation Assay

Hek293T cells were transfected with expression plasmids for human TGR5 plasmid and CRE-driven luciferase reporter constructs. Cells were exposed to vehicle alone or 1$100 \mu \mathrm{M}$ of the UDCA analogues indicated. Luciferase activity in the cell extract was normalized to Renilla luciferase activity for each well and expressed as fold induction relative to vehicle-exposed cells. The values are means \pm S.D. of three experiments. Compounds in the figure are indicated by bracketed numbers.

UDCA analogues possessing a $7 \beta$-hydroxy group and investigated their abilities for TGR5-selective agonist activity.

Epimerization of the $3 \alpha$-hydroxyl group of UDCA did not stimulate TGR5 agonist activity (Fig. 3A). This result was consistent with previous observations of the $3 \beta$-epimers of LCA and CDCA exhibiting lower affinities for TGR5 than LCA and CDCA, respectively. ${ }^{27)} 7 \beta$-Hydroxy-3-oxo-5 $\beta$ cholanoic acid (3), the 3-oxo form of UDCA, exhibited weaker TGR5 agonist activity than UDCA (Fig. 3A), inconsistent with the previously reported finding that oxidation of the $3 \alpha$-hydroxyl group in bile acids leads to an enhancement of their activity. ${ }^{27)}$ The existence of $7 \beta$-hydroxyl group may subtly affect the interaction between ligand-binding site of TGR5 and the oxygen atom at the C-3 position.

In this study, we synthesized two noble compounds that a methyl group were introduced at the C-3 position of UDCA, and examined the effect of these compounds on TGR5 activation. The TGR5 activation ability of 3-methylated UDCA analogues ((4), (5)) did not differ as compared with that of UDCA, and their affinity for TGR5 was decreased by approximately four-fold and two-fold, respectively, as suggested by the $\mathrm{EC}_{50}$ values (Fig. 3A). These findings indicate that steric hindrance by a bulky substituent at the C-3 position may cause a reduction of the ligand potency.

$7 \xi$-Methyl-LCA had a much higher ability for TGR5 activation as compared to LCA, the most potent endogenous TGR5 agonist. $^{27)}$ In addition, it has been shown that an increase in the carbon chain length of the alkyl substituent in $7 \beta$-alkylated CDCA resulted in a gradual increase of the TGR5 agonist activity. ${ }^{27)}$ In the present study, $7 \alpha$-methylated 
Table 1. TGR5 Selectivity of UDCA Analogues

\begin{tabular}{|c|c|c|c|c|c|}
\hline \multirow{2}{*}{ Compounds } & \multicolumn{2}{|c|}{ TGR5 } & \multicolumn{2}{|c|}{ FXR } & \multirow{2}{*}{$\mathrm{TGR} / \mathrm{FXR} \mathrm{EC}_{50}$ ratio } \\
\hline & Efficacy $(\%)$ & $\mathrm{EC}_{50}(\mu \mathrm{M})$ & Efficacy (\%) & $\mathrm{EC}_{50}(\mu \mathrm{M})$ & \\
\hline UDCA & 81.0 & 14.9 & 41.0 & 21.5 & 0.69 \\
\hline UDC-tau & 83.6 & 12.2 & 8.1 & 41.2 & 0.30 \\
\hline UDC-gly & 79.2 & 15.1 & 7.9 & 25.0 & 0.60 \\
\hline (1) & 56.6 & 16.3 & 32.9 & 23.5 & 0.70 \\
\hline (2) & 49.5 & 14.4 & 22.7 & 28.4 & 0.51 \\
\hline (3) & 48.6 & 13.4 & 30.1 & 22.4 & 0.60 \\
\hline (4) & 71.8 & 59.4 & 24.3 & 12.7 & 4.69 \\
\hline (5) & 60.0 & 26.6 & 25.3 & 11.4 & 2.34 \\
\hline (6) & 100.1 & 1.9 & 24.0 & 18.2 & 0.10 \\
\hline (7) & 6.0 & 11.2 & 7.5 & n.d. & n.d. \\
\hline (8) & 71.1 & 5.8 & 8.9 & n.d. & n.d. \\
\hline (9) & 0.0 & n.d. & 5.4 & 1.0 & n.d. \\
\hline (10) & 136.7 & 6.5 & 234.5 & 28.1 & 0.23 \\
\hline (11) & 79.4 & 0.9 & 5.9 & 6.3 & 0.14 \\
\hline
\end{tabular}

Data represent average values of at least three independent experiments of CRE-driven luciferase reporter assays in TGR5-transfected Hek293T cells. Units are $\mu \mathrm{M}$ for EC ${ }_{50}$ and $\%$ of $1 \mu \mathrm{M}$ LCA value for efficacy. FXR agonist activities were determined as described in Materials and Methods; units are $\mu \mathrm{M}$ for EC and $_{50}$ a of $10 \mu \mathrm{M}$ CDCA value for efficacy. The compounds in the table are indicated by the bracketed numbers.

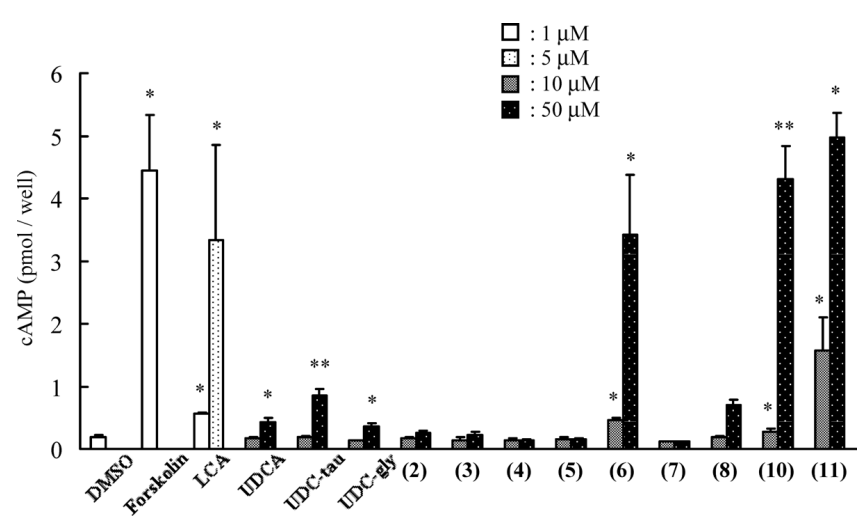

Fig. 4. hTGR5-Transfected Hek293T Cells Produced cAMP after Stimulation with Forskolin or LCA or UDCA Analogues

Hek293T cells were transfected with an hTGR5 expression plasmid. Then, the cells were stimulated with vehicle (DMSO) only, forskolin, LCA or various UDCA analogues at $37^{\circ} \mathrm{C}$ for $30 \mathrm{~min}$. cAMP production were then determined. The data represent the mean \pm S.D. of three determinations. The compounds in the figure are indicated by the bracketed numbers. $* p<0.05 ; * * p<0.01$ versus vehicle (DMSO)-treated cells.

UDCA (6) exhibited higher affinity for TGR5 than any other UDCA analogues, and thus, we demonstrated that the introduction of an alkyl group in position $7 \alpha$ of the bile acid improves the TGR5 agonist activity (Fig. 3A). It is also supported by the finding that $7 \alpha$-methylated UDCA (6) exhibited significantly cAMP-production capacity even at a concentration of $10 \mu \mathrm{M}$ (Fig. 4). In contrast, sulfuric acid conjugation of $7 \beta$-hydroxyl group (7) diminished the activity (Fig. $3 \mathrm{~A})$. Considering these results together with the previous findings, ${ }^{27)}$ it may be implied that the region interacting with the $\mathrm{C}-7$ position of bile acids in the TGR5-binding site should be a sufficiently spacious and hydrophobic pocket.

Since we have previously shown that taurine- or glycineconjugated bile acids have generally higher affinities in comparison with unconjugated bile acids, ${ }^{27)}$ we investigated whether UDCA conjugated with various amino acids might have a higher TGR5 agonist potency. As shown in Fig. 3B, UDC-PABA (10), UDCA conjugated with $p$-aminobenzoic acid, exhibited higher TGR5 agonist activity at the concentration of $100 \mu \mathrm{M}$ as compared with LCA $(1 \mu \mathrm{M})$, whereas the activities of the other amino acid conjugates were weaker. In addition, the highest cAMP production was observed when the cells were treated with UDC-PABA (10) (Fig. 4).

Finally, the TGR5/FXR selectivity of UDCA analogues was estimated by calculating the ratio of the $\mathrm{EC}_{50}$ for TGR5 to that for FXR (TGR5/FXR $\mathrm{EC}_{50}$ ratio) (Table 1). Although, most UDCA analogues showed less than $30 \%$ of the ability for FXR activation as compared with CDCA, the FXR agonist activity of UDC-PABA (10) was over two-fold higher than that of $10 \mu \mathrm{M}$ of CDCA (Table 1). Since a decrease of the TGR5/FXR EC ${ }_{50}$ ratio was observed, however, these findings implies that further preparation of conjugated bile acids will contribute to the advancement of TGR5 agonists.

In addition, the $\mathrm{TGR} 5 / \mathrm{FXR} \mathrm{EC}_{50}$ ratio significantly decreased by the introduction of a methyl group at the $\mathrm{C}-7 \alpha$ position of UDCA, indicating an augmentation of TGR5 selectivity, whereas other UDCA analogues tested in this study did not have the same effect. Alkyl substitution at the C-7 position of bile acids seems to result in both an increase in the affinity for TGR5 and a decrease in the affinity for FXR, as previously indicated. ${ }^{27)}$

In conclusion, we demonstrated the possibility of $7 \alpha$ methylated UDCA being an effective TGR5-selective agonist, though newly synthesized 3-methylated UDCA analogues were not a potent TGR5 agonist. Since the present and previous studies indicated that the size of hydrophobic substituent introduced at C-7 position affects both TGR5 and FXR agonist activities, ${ }^{10,27)}$ it is likely that UDCA possessing an ethyl or propyl group at the $\mathrm{C}-7 \alpha$ position would become more selective and stronger TGR5 agonist.

Acknowledgements This work was supported in part by a Grant from the Japan Health Sciences Foundation.

\section{REFERENCE}

1) Hagey L. R., Crombie D. L., Espinosa E., Carey M. C., Igimi H., Hofmann A. F., J. Lipid Res., 34, $1911-1917$ (1993).

2) Nakagawa S., Makino I., Ishizaki T., Dohi I., Lancet, 2, 367-369 (1977).

3) Omata M., Yoshida H., Toyota J., Tomita E., Nishiguchi S., Hayashi 
N., Iino S., Makino I., Okita K., Toda G., Tanikawa K., Kumada H., Gut, 56, 1747-1753 (2007).

4) Sato S., Miyake T., Tobita H., Oshima N., Ishine J., Hanaoka T., Amano Y., Kinoshita Y., World J. Gastroenterol., 15, 2782-2786 (2009).

5) Poupon R. E., Lindor K. D., Cauch-Dudek K., Dickson E. R., Poupon R., Heathcote E. J., Gastroenterology, 113, 884—890 (1997).

6) Makishima M., Okamoto A. Y., Repa J. J., Tu H., Learned R. M., Luk A., Hull M. V., Lustig K. D., Mangelsdorf D. J., Shan B., Science, 284, 1362-1365 (1999).

7) Parks D. J., Blanchard S. G., Bledsoe R. K., Chandra G., Consler T. G., Kliewer S. A., Stimmel J. B., Willson T. M., Zavacki A. M., Moore D. D., Lehmann J. M., Science, 284, 1365-1368 (1999).

8) Zhang Y., Lee F. Y., Barrera G., Lee H., Vales C., Gonzalez F. J., Willson T. M., Edwards P. A., Proc. Natl. Acad. Sci. U.S.A., 103, 10061011 (2006).

9) Ma K., Saha P. K., Chan L., Moore D. D., J. Clin. Invest., 116, 11021109 (2006).

10) Fujino T., Une M., Imanaka T., Inoue K., Nishimaki-Mogami T., $J$. Lipid Res., 45, 132-138 (2004).

11) Maruyama T., Miyamoto Y., Nakamura T., Tamai Y., Okada H., Sugiyama E., Itadani H., Tanaka K., Biochem. Biophys. Res. Commun., 298, 714-719 (2002)

12) Kawamata Y., Fujii R., Hosoya M., Harada M., Yoshida H., Miwa M., Fukusumi S., Habata Y., Itoh T., Shintani Y., Hinuma S., Fujisawa Y., Fujino M., J. Biol. Chem., 278, 9435-9440 (2003).

13) Thomas C., Pellicciari R., Pruzanski M., Auwerx J., Schoonjans K., Nat. Rev. Drug Discov., 7, 678-693 (2008).

14) Watanabe M., Houten S. M., Mataki C., Christoffolete M. A., Kim B. W., Sato H., Messaddeq N., Harney J. W., Ezaki O., Kodama T., Schoonjans K., Bianco A. C., Auwerx J., Nature (London), 439, 484489 (2006).
15) Batta A. K., Aggarwal S. K., Salen G., Shefer S., J. Lipid Res., 32, 977-983 (1991).

16) Lack L., Dorrity F. O. Jr., Walker T., Singletary G. D., J. Lipid Res., 14 $367-370$ (1973).

17) Tserng K. Y., Hachey D. L., Klein P. D., J. Lipid Res., 18, 404-407 (1977).

18) Parmentier G., Eyssen H., Steroids, 30, 583-590 (1977).

19) Une M., Cohen B. I., Mosbach E. H., J. Lipid Res., 25, 407-410 (1984).

20) Trifonova A., Diesen J. S., Chapman C. J., Andersson P. G., Org. Lett., 6, 3825-3827 (2004).

21) Dalling D. K., Grant D. M., Johnson L. F., J. Am. Chem. Soc., 93, 3678-3682 (1971)

22) Mosmann T., J. Immunol. Methods, 65, 55-63 (1983).

23) Fiorucci S., Mencarelli A., Palladino G., Cipriani S., Trends Pharmacol. Sci., 30, 570-580 (2009).

24) Lefebvre P., Cariou B., Lien F., Kuipers F., Staels B., Physiol. Rev., 89, 147-191 (2009).

25) Nishimaki-Mogami T., Une M., Fujino T., Sato Y., Tamehiro N., Kawahara Y., Shudo K., Inoue K., J. Lipid Res., 45, 1538-1545 (2004).

26) Nishimaki-Mogami T., Kawahara Y., Tamehiro N., Yoshida T., Inoue K., Ohno Y., Nagao T., Une M., Biochem. Biophys. Res. Commun. 339, 386-391 (2006).

27) Sato H., Macchiarulo A., Thomas C., Gioiello A., Une M., Hofmann A. F., Saladin R., Schoonjans K., Pellicciari R., Auwerx J., J. Med. Chem., 51, 1831-1841 (2008).

28) Iguchi Y., Kihira K., Nishimaki-Mogami T., Une M., Steroids, 75, 95-100 (2010)

29) Iguchi Y., Yamaguchi M., Sato H., Kihira K., Nishimaki-Mogami T., Une M., J. Lipid Res., 51, 1432-1441 (2010). 